\title{
RHEUMATOID ARTHRITIS ACTIVITY AND BODY MASS INDEX
}

Kamilla de Bessa Jorge ${ }^{1, \star}$, Naiana Diaz ${ }^{1}$, Ana Luísa Diomedes Sardinha ${ }^{1}$, Carolina Weibel Thomé1 ${ }^{1}$ Thelma L Skare ${ }^{1}$, Bárbara Stadler Kahlow ${ }^{1}$

1.Hospital Universitário Evangélico Mackenzie, Curitiba (PR), Brazil.

*Corresponding author: kamillabessajorge@gmail.com

\section{BACKGROUND}

Rheumatoid arthritis (RA) and obesity are both chronic inflammatory diseases. It is believed that obesity may intervene in RA inflammatory parameters. Association of RA and obesity is not uncommon. The physical inactivity imposed by pain and deformities and use of glucocorticoid are some implicated factors in this association. In this context obesity is not only detrimental for patient's cardiovascular risk, but also for the inflammatory process of the disease. The aim of this study was to verify a possible correlation between body mass index (BMI) and inflammatory activity in a sample of RA patients.

\section{METHODS}

Cross-sectional observational study of RA patients in which biometric data (weight and high) for BMI calculation and inflammatory parameters were obtained. The inflammatory parameters included: erythrocyte sedimentation rate (ESR); C reactive protein (CRP), disease activity score (DAS) 28-ESR and DAS 28-CRP.

\section{RESULTS}

A total of 676 patients ( $87.5 \%$ women with a median age of 59.6 years) were included. In this population: $1.3 \%$ were under normal weight; $28.1 \%$ within normal weight; $35.3 \%$ were overweight; $31 \%$ had grade I obesity and $4.1 \%$ had grade 2 obesity. A weak correlation was found between DAS28-CRP with BMI ( $r h o=0.11, p=0.005)$. Correlations with other inflammatory parameters were nonsignificant $(p>0.05)$.

\section{CONCLUSION}

There was a high proportion of RA patients with above normal weight in the studied sample. A weak correlation between BMI and DAS28-PCR was found.

\section{KEYWORDS}

Rheumatoid arthritis, Body mass index, Obesity, Inflammation. 